\title{
THE WEIGHT OF VEGETATION TRANSPORTED BY TROPICAL FUNGUS ANTS.
}

\author{
By G. H. Parkar. \\ Zoological Laboratory, Harvard University.
}

No one can view a nest of active tropical fungus ants without being impressed by the unusual exhibition of transportation. Converging narrow paths are crowded with myriads of ants many of the incoming members of which carry above their heads the fragments of leaves, bits of stems and the like destined to serve as the soil on which the colony will raise its food. Such a spectacle came to my attention not far from the Barro Colorado Island Laboratory in Gatun Lake, at the Panama Canal. The colony was in an open part of the jungle about a quarter of a mile from the laboratory and easily accessible by a trail. At this laboratory, which is maintained by the Institute for Research in Tropical America, I had the opportunity of studying this and many other features of equatorial life.

The nest was inhabited by the common fungus ant of the region, Atta columbica Guér., and comprised an approximately circular area of hummocky soil some twelve to fifteen feet in diameter. Into this area from various parts of the jungle led in all five ant-roads over which varying numbers of ants passed in and out with their burdens. It was comparatively easy to stand at a given point by one of these roads and, with a watch in the hand, count the number of ants with leaf fragments that passed toward the nest in a minute. Twenty such counts were made on each of the five roads.

In the most densely frequented road the numbers of leaf fragments carried past the observer in a minute varied from 151 to 184 and averaged 162.8. In the second most populous road the extremes were 52 and 81 and the average 69 . In the third the numbers varied between 49 and 61 and averaged 53 ; in the fourth the extremes were 1 and 6 , and the average 3.2 , and in the fifth, which descended from a small tree that rose out of the nest, the numbers varied from 0 to 5 , and averaged 2.2. As these five roads were separate pathways leading into the nest, the sum of 
their several averages, 290.2, represents the total average number of leaf fragments that were brought into the nest each minute.

One hundred of these leaf fragments were taken from the transporting ants and weighed; their weight proved to be 1.164 grams. If on the average a total of 290.2 fragments were carried into the nest each minute, the weight of vegetation added per minute must then have been a little over 3.35 grams. In an hour at this rate it would amount to 201 grams and in twelve hours to a little over 2.4 kilograms or some five and a quarter pounds. I do not know whether these ants work during the night. If they do so even at a lowered speed, the weight of vegetation added per day to the nest must be of course much more than five and a quarter pounds. The records here set down refer to daylight conditions toward the end of June. Incidentally it may be added that the rate of travel of an individual ant carrying a leaf fragment during the warm hours of the day in June varied from 1.5 to 1.2 meters per minute and averaged on ten counts 1.3 meters per minute. These incidental notes seemed worthy of record. 


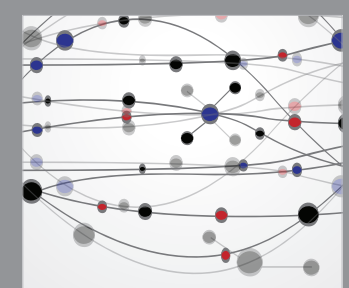

The Scientific World Journal
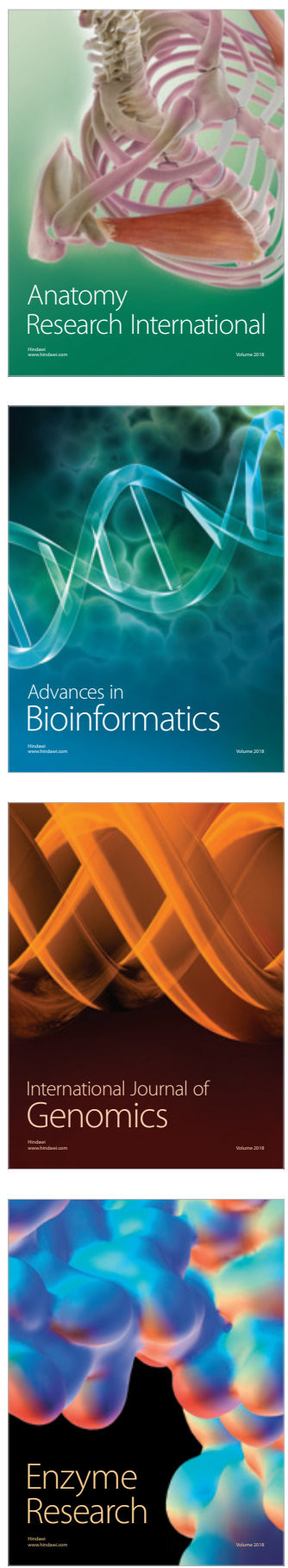
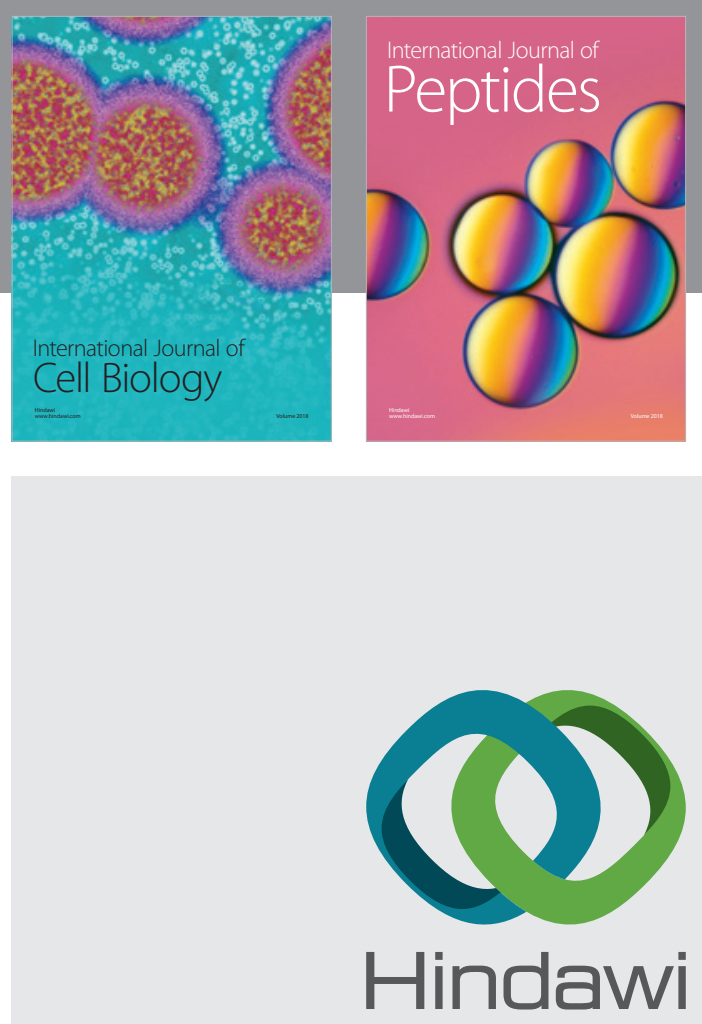

Submit your manuscripts at

www.hindawi.com
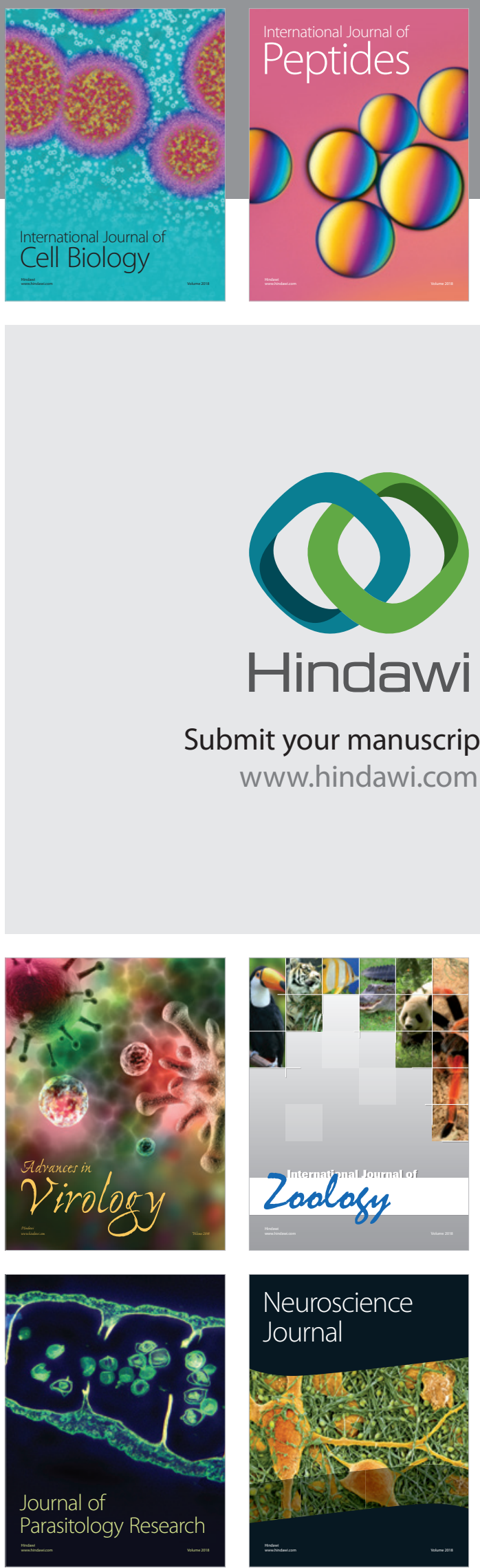
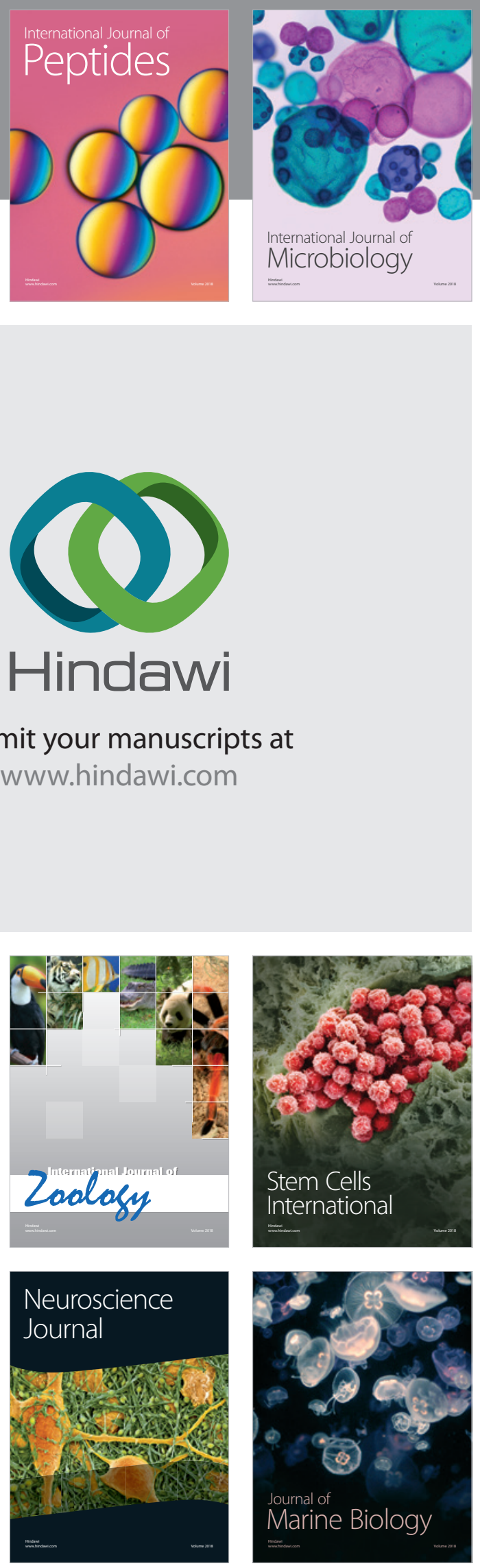
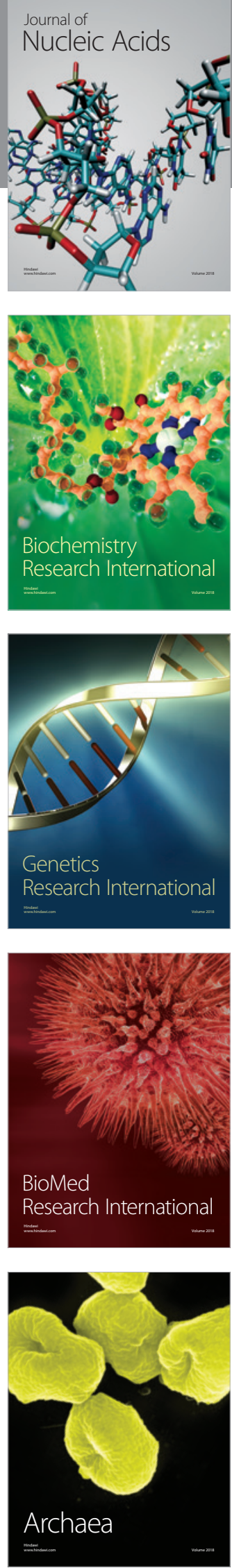